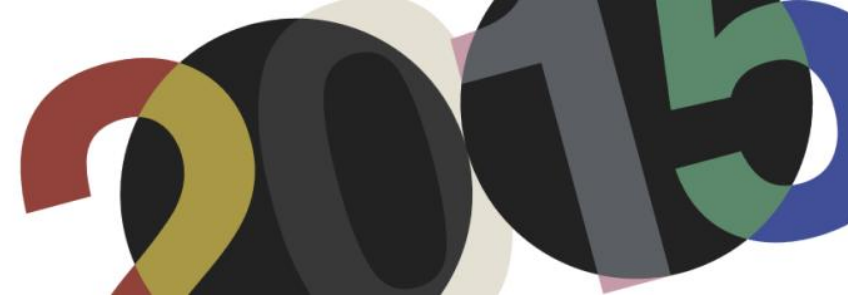

DOI: http://dx.doi.org/10.4995/LC2015.2015.669

\title{
Arquitectura y tapiz de Le Corbusier. La trama y la urdimbre de la casa nómada
}

\section{A. Gelabert Amengual}

Escuela Técnica Superior de Arquitectura de Madrid

\begin{abstract}
Resumen: Durante la primera mitad del siglo XX Le Corbusier tuvo sus primeras experiencias con los tapices de la mano de la galerista Marie Cuttoli y, sobre todo, de Pierre Baudouin, profesor de Aubusson. El arquitecto no dudó en colocar su producción de cartones para tapices a la altura del resto de su creación artística, como ya hicieran antes Leger o Picasso. Comenzó entonces una reflexión sobre las propiedades tanto plásticas como acústicas de los tapices que tuvo oportunidad de experimentar en obras tan importantes como Chandigarh o el Hospital de Venecia. Todas las consideraciones al respecto fueron recogidas después en varios capítulos de sus Obras Completas. Pero fue en la vivienda donde Le Corbusier reconoció el mayor potencial para el tapiz. Fue en el espacio doméstico donde sus experiencias con el tejido adquirieron su máxima trascendencia, llegando a elaborar un discurso que entronca directamente con las disquisiciones de Semper y Loos sobre la potencia espacial del tapiz, al que otorgaba la capacidad de generar la casa para el hombre que la década de los 60 está moldeando.
\end{abstract}

Abstract: During the first half of the twentieth century Le Corbusier had his very first experiences with tapestries thanks to the gallery director Marie Cuttoli and especially the teacher at Aubusson, Pierre Baudouin. The architect had no doubt in putting his production of tapestry cartoons at the same level of the rest of his artistic creations, as Leger or Picasso did before. Then he began a reflection on both plastic and acoustic properties of the tapestries, which he experienced in such important works as Chandigarh or the Venice Hospital. All considerations in this regard were collected in several chapters of his Complete Works. But it is in the home where Le Corbusier recognized the greatest potential for the tapestry. It is in the domestic space where his experiences with tissue acquired their utmost importance. He elaborated a discourse that connects directly with the disquisitions of Semper and Loos on the spatial power of tapestry, and that gives it the ability to generate the home for the man that the 60 s decade is molding.

Palabras clave: Tejido; tapiz; Semper; casa; nómada; contingencia.

Keywords: Tissue; tapestry; Semper ; home; nomad ; contingency.

\section{Le Corbusier en Aubusson}

Le Corbusier mantuvo a lo largo de su vida una estrecha relación con los tapices, que consideraba a la altura de cualquiera de las otras artes plásticas. Su vinculación con el arte textil es explicada con detalle en un artículo que publica en 1960 en la revista Zodiac y que titula Tapisseries Muralnomad.

“Estuve encantado de tener que abordar un día el problema del tapiz ${ }^{1}$." Le Corbusier

El texto relata cómo fue Marie Cuttoli quien le encargó el primer cartón ${ }^{2}$ para tapiz. Cuttoli, galerista y coleccionista francesa, ya había encargado obras en esta misma técnica a otros grandes artistas de la época como

\footnotetext{
${ }^{1}$ Le Corbusier, Tapisseries Muralnomad
} 
Picasso, Léger, Miró, Calder. Había sido ella, alrededor de 1935, la que propició el resurgir de esta industria casi abandonada entonces en Francia.

Pero fue un antiguo profesor de dibujo de la fábrica de tapices de Aubusson, Pierre Baudouin quien a través de sus encargos conseguiría que Le Corbusier se dedicara más intensamente a la confección de cartones, confirmando su interés por la relación entre plástica y tejido, entendido tejido como sustantivo y como adjetivo: como trabajo terminado y como proceso de ejecución.

Al final de su vida Le Corbusier había realizado unos treinta cartones para tapices. En su correspondencia quedaron además otros proyectos como los tapices con el león heráldico de San Marcos para el Hospital de Venecia, o las propuestas de Jörn Utzon para que se encargara de otros destinados a la Ópera de Sidney ${ }^{3}$.

El arquitecto francés dedicó además varios capítulos de sus Obras Completas a estos objetos. A través de textos e imágenes, expone de qué forma el tapiz responde al espíritu de su tiempo en la creación artística, y se expresa con una tridimensionalidad plástica cercana a la del propio proyecto de arquitectura. El espacio tejido manifiesta lo tectónico, lo ontológico, lo táctil. La trama y la urdimbre son cruciales en el tejido del espacio, tanto estructuralmente como en su dimensión atmosférica.

En su obra, Le Corbusier no diferencia entre sus trabajos para tapices, pinturas, esculturas, libros, edificios o planeamientos urbanos. Todo es para él una sola misma manifestación artística del espíritu de su época. Sus tapices contienen una arquitectura latente, que puede ser desvelada siguiendo las pistas que para ello nos dejó el arquitecto. Los dibujos en los tapices incluyen las potencialidades de unas plantas (y sus correspondientes secciones) que pueden llegar a ser.

“El trazado regulador es una seguridad contra lo arbitrario ${ }^{4 ”}$ Le Corbusier.

Las composiciones para tapices se convierten en fuente de inspiración plástica para sus edificios. En la búsqueda de trazados reguladores, la trama y la urdimbre constituyen una referencia eficaz para su trabajo.

Así, resulta que algunas arquitecturas de Le Corbusier se tejen. La trama y la urdimbre se manifiestan de forma más o menos aparente en las plantas de algunas de sus obras, se entrecruzan y conforman un espacio tridimensional complejo que es el espacio propuesto por el arquitecto para la nueva sociedad maquinista que quiere alumbrar a través de su trabajo.

\footnotetext{
${ }^{2}$ Según el diccionario de la Real Academia Española (RAE), 22 a ed., el cartón es el 7. m. Pint Dibujo sobre papel o lienzo, a veces colorido, de una composición o figura, ejecutado en el mismo tamaño que ha de tener la obra de pintura, mosaico, tapices o vidriería para la que servirá de modelo.

${ }^{3}$ Tal y como expone el profesor Juan Calatrava en su texto Le Corbusier, 1955: en los alrededores del El poema del ángulo recto en Juan Calatrava (ed.), Doblando el ángulo recto. 7 ensayos en torno a Le Corbusier. Madrid: Área de Edición del Círculo de Bellas Artes, 2009. 199 p.

4 "Del nacimiento fatal de la arquitectura. La obligación del orden. El trazado regulador es una seguridad contra lo arbitrario. Procura la satisfacción del espíritu. El trazado regulador es un medio; no es una receta. Su elección y sus modalidades de expresión son parte integrante de la creación arquitectónica." Le Corbusier: Vers unes architecture, p. XXIV
} 
A su vez, las descripciones sobre las propiedades atmosféricas, e incluso sociales o económicas, de los tapices muestran cuáles serán las cualidades que se derivarán del uso de esa técnica en la construcción de los edificios, tanto públicos como privados; se atreve incluso a vaticinar quién será el habitante de la casa construida con tapices.

Elabora en este sentido un discurso que entronca directamente con las reflexiones de Gottfried Semper reivindicando el papel de lo textil en los orígenes mismos de la arquitectura, de la estera como el más primitivo divisor del espacio. Semper, como Le Corbusier, atribuye al elemento textil la capacidad de construir por sí mismo el espacio social, más allá del soporte que pudieran darle el resto de elementos.

"Los tapices colgantes eran los verdaderos muros, los límites visibles de espacio. Las paredes sólidas a menudo detrás de ellos eran necesarias por razones que no tenían nada que ver con la creación de espacios; eran necesarias para la seguridad, para soportar una carga, para su permanencia y así sucesivamente. Donde no se planteó la necesidad de estas funciones secundarias, los tapices se mantuvieron como los medios originales de separación del espacio. Incluso cuando se hizo necesaria la construcción de muros sólidos, sólo eran la estructura interna, una estructura invisible escondida detrás de los representantes verdaderos y legítimos del muro, los coloridos tapices tejidos. ${ }^{5}$ " Gottfried Semper

Este posicionamiento es válido en el terreno privilegiado para el uso del tapiz: la vivienda. La misma técnica, en cambio, cumple una función distinta al salir del espacio doméstico. En los edificios públicos ya no es más el encargado casi único de la construcción de los espacios, sino que pasa a jugar un papel mucho más tecnológico, su rol será crucial en cuanto al control de las propiedades acústicas de las grandes construcciones de hormigón armado. Los tapices devienen entonces tapisseries acoustiques. El tapiz sigue, en cualquier caso, ligada a la definición atmosférica del edificio.

\section{Propiedades plásticas, propiedades atmosféricas}

La primera vez que aparecen los tejidos en la Obra Completa es en el Volumen 3: 1934-1938 en la Exposition d'art dit 'Primitif' de Louis Carré en el apartamento de Le Corbusier (1935). En las dos páginas que se le dedican en la publicación, se muestra algún tapiz de Leger de forma recurrente (concretamente, aparece en tres de la cuatro imágenes que ilustran la exposición). El proyecto que sigue inmediatamente es el Pavillon des 'Temps Nouveaux'. La construcción de este pabellón para la Exposición Internacional de París de 1937, con cables y lonas, cierra un espacio cuya dirección estructural (urdimbre) es tejida tridimensionalmente por los recorridos (trama). Los accesos se producen en dirección perpendicular a la de los pilares metálicos, y en la misma se desarrollan las rampas que recorren el pabellón; una arquitectura tejida relatada tras una exposición en la que el tapiz resulta la obra más destacada.

Tras el proyecto de Chandigarh, el tapiz adquiere una nueva dimensión en la obra de Le Corbusier, debido en gran parte a la estrecha relación que mantuvo con los tejedores de Kashmir durante su experiencia en la India. Y es así como en el Volumen 6: 1952-1957 se dedica un capítulo íntegro del índice a las Tapisseries, en el que a lo largo de dos páginas de la Obra Completa se relatan varias de sus experiencias con los tapices: desde su relación con Pierre Baudouin en Aubusson, hasta los tapices para Chandigarh pasando por el cartón para el arquitecto

\footnotetext{
${ }^{5}$ Gottfried Semper: The Four Elements of Architecture, en The Four Elements of Architecture and other Writings, p. 104
} 
japonés Sakakura. Además, y sobre todo, se apunta aquí por primera vez la vinculación del tapiz con el hombre nómada que está surgiendo en esa época, una relación desarrollada en el texto Tapisseries Muralnomad al que se hacía referencia en el arranque del presente texto.

Todas estas explicaciones preceden al proyecto de la Villa Shodan (Ahmedabad, 1951). La casa Shodan no tiene una dirección clara: los vientos soplan en una dirección, la estructura se dispone en la otra; la casa parece mirar en la primera, la circulación principal con la rampa se desarrolla en la otra; el acceso se produce en la primera dirección, el pavimento se ordena en la perpendicular... Los espacios se cruzan constantemente en distintos planos, las direcciones se atan conformando un edificio tejido.
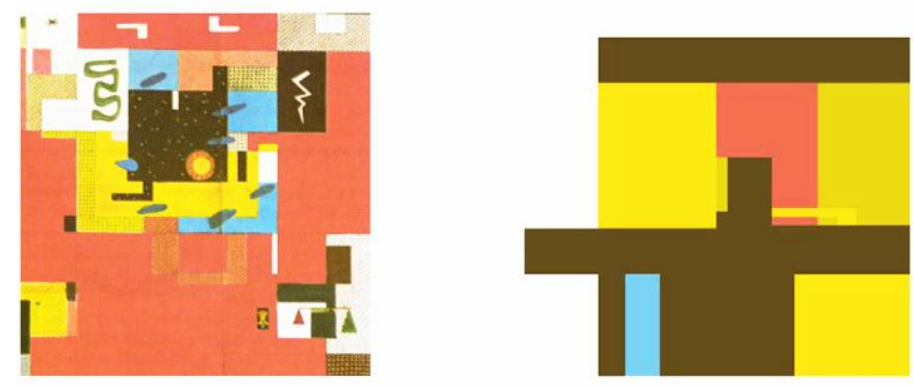

1. Uno de los tapices que preceden el proyecto de la casa Shodan en el Volumen 6 de la Obra Completa (izq.). Plantas superpuestas de la casa Shodan (der.)

Tras haber ofrecido varias pistas con los proyectos descritos hasta ese punto, en las páginas dedicadas al Capitolio de Chandigarh en el Volumen 8: 1965- 1969 les dernieres ouvres de las Obras Completas el enlace entre tapiz y composición arquitectónica se hace ya explícito. Con el último tapiz de la serie dedicada a Chandigarh y diseñados para el Palacio de la Justicia, Le Corbusier desvela abiertamente la relación plástica que existe entre el diseño de sus tapices y algunos de sus edificios. Ese último tapiz aparece ocupando toda una página (par) y al otro lado, ocupando también la página completa (impar) la planta del segundo proyecto para el Hospital de Venecia (1965). Entre uno y otra podemos leer: L'étonnante ressemblance des formes.

Incluso de forma más clara que en la Villa Shodan, en el Hospital de Venecia dos direcciones se cruzan: en los tres niveles del edificio de nuevo encontramos dos direcciones estructurales, dos direcciones de circulación, dos direcciones de iluminación, dos direcciones de compartimentación, dos direcciones de mobiliario... que también en esta ocasión se cruzan tejiendo un edificio-tapiz. El nudo semperiano como manifestación del estado tensional de la arquitectura. 

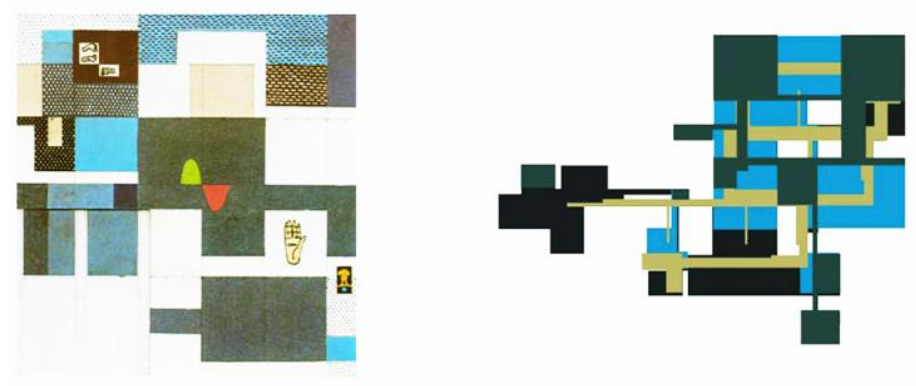

2. Uno de los tapices que preceden al Hospital de Venecia en el Volumen 8 de la Obra Completa (izq.). Plantas superpuestas del Hospital de Venecia (der.)

Existe por lo tanto un camino bidireccional que va desde los proyectos de las dos últimas obras citadas anteriormente (Shodan y Hospital de Venecia) hasta los diseños de los cartones para los tapices de Chandigarh. La superposición de las plantas de esos edificios muestra su doble dirección y el cruce de los espacios en su voluntad de tejerse, la asombrosa similitud de formas no es casual.

Pero es que es posible emprender también un camino complementario: el que parte de los tapices para llegar a las arquitecturas a través de su definición atmosférica.

Como se ha citado, los tapices (y la acústica del Capitolio de Chandigarh) ocupan un espacio muy importante al final de la Obra Completa. Toda esa extensión, que acaba con L'étonnante ressemblance des formes es en realidad dedicada a describir la importancia atmosférica de los elementos textiles en los espacios construidos en hormigón armado. En las 13 páginas completas dedicadas a versar sobre las propiedades de los tapices que cuelgan en el Capitolio, se mencionan cuestiones como la escala, la simbología, la acústica o el cromatismo:

"Los 650m2 de tapices fueron fabricados en los talleres de Kashmir en 1955 y 1956. Los habilidosos tejedores de tapices en India apenas necesitaron cinco meses para completar el trabajo. Ocho tapices de 64m2 cada uno y uno de 144m2 cuelgan de las paredes traseras de las salas del Palacio de Justicia.

En el edificio del Parlamento, también, los tapices cumplen una función acústica. Cuando el visitante accede por la entrada baja a oeste del Parlamento, experimenta un espectáculo arquitectónico apabullante. Entra en un hall alto, sombreado, fresco. En el muro norte, tras las columnas y la rampa, hay un tapiz azul-rojizo de 25 metros de largo extendiéndose de suelo a techo y cubierto con motivos simbólicos. Además de su función óptica, también tiene una finalidad acústica. ${ }^{6, "}$ Le Corbusier

Le Corbusier ya había hablado de ese papel fundamental del tapiz en la definición atmosférica de los grandes edificios de hormigón armado en el texto Tapisseries Muralnomad, en el que hace referencia explícita tanto a las salas de tribunal del Palacio de Justicia de Chandigarh como a la gran sala de teatro de Sakakura, para quien realizó un cartón 1956. Este tapiz, de $230 \mathrm{~m}^{2}$, serviría como telón del teatro Bunka Kaikan de Tokyo. El mismo cometido cumplen los tapices para Chandigarh, colgados en las paredes del Palacio de Justicia y que fueron

\footnotetext{
${ }^{6}$ Le Corbusier: Le Corbusier: les dernières oeuvres [1965-1969], p. 118
} 
colocados por razones acústicas, y con la voluntad de situar uno junto al otro el trabajo en hormigón armado del arquitecto (resonante) y el trabajo en lana de los artesanos (absorbente acústico). El tapiz se convierte aquí en un instrumento privilegiado para el encuentro entre plástica y arquitectura.

\section{Mural-nómada}

Pese a haberlos utilizado en varias ocasiones en sus edificios públicos, Le Corbusier siempre consideró que el terreno privilegiado de la recuperación moderna de la actividad textil era la vivienda, la escala doméstica. Desde el momento en que el tapiz constituye un tema con entidad propia en su obra, Le Corbusier determina que éste debe cambiar su uso. Ya no formará nunca más parte del mobiliario de la vivienda, no deberá asemejarse a cualquier otro mueble auxiliar, ni en tamaño ni en posición. Ni siquiera es para él un cuadro, enmarcado y suspendido en el centro de un vano. El tapiz debe ocupar una pared de suelo a techo, y construirse según las dimensiones del Modulor (226-296-366 cm) con la voluntad de ajustarse a la medida del hombre. Dejará de ser entonces un adorno para convertirse en un elemento más en la composición arquitectónica, un elemento capaz de ordenar el espacio interior de la vivienda ${ }^{7}$. El tapiz es el Mural de los tiempos modernos, que han convertido al hombre en nómada.

“(...) jel hombre moderno es un nómada! Nuestro nómada cambia de casa porque su familia ha crecido, o, por el contrario, porque sus hijos se han casado. El tapiz le da la posibilidad de proveerse de un 'mural', es decir, una pintura de grandes dimensiones, de potencial arquitectónico. Desenrolla su tapiz y lo despliega sobre el muro, hasta el suelo. ¿Quiere mudarse? Enrolla su 'mural', lo pone bajo su brazo y baja las escaleras para instalarse en su nueva ubicación. " Le Corbusier

La potencialidad arquitectónica deviene el atributo fundamental del tapiz, que ha dejado de ser un objeto decorativo para se un objeto conformador del espacio. Es aquí donde el vínculo con las propuestas de Semper se hace más evidente, ya que mientras que en los grandes edificios públicos el tapiz trabaja frente al hormigón, matizando sus propiedades, aquí el tapiz sustituye al muro, que deja de ser necesario para levantar la casa El tapiz es el elemento que resuelve el nuevo interés por el arte de una nueva sociedad en constante movimiento. No es posible pintar un mural en las paredes de un apartamento que se abandonará al cabo de unos años, en cuanto la situación familiar cambie. Su función en cualquier caso "no es la de potenciar el muro; por el contrario significa una destrucción violenta del mismo, haciéndole perder sus valores de estabilidad, peso, etc", como dice Le Corbusier en 1932 en una carta a Vladimir Nekrassov. Juega un papel crucial en la apropiación del espacio. El tapiz es el 'mural del nómada' que colma en los hogares un deseo poético de sus habitantes. Introduce una serie de nuevas relaciones, con su textura, su materia, la lectura de su proceso de confección. La impronta manual del elemento constructivo, o la energía viva de la arquitectura repercutiendo sobre el usuario.

\footnotetext{
${ }^{7}$ En el mismo sentido, Adolf Loos afirmará que la tarea del arquitecto es la definición de los elementos textiles que conforman el espacio: "Pongamos que el arquitecto tuviera aquí la misión de hacer un espacio cálido y habitable. Las alfombras son cálidas y habitables. Este espacio podría resolverse poniendo una de ellas en el suelo y colgando cuatro tapices de modo que formaran las cuatro paredes. Pero con alfombras no puede construirse una casa. Tanto la alfombra como el tapiz requieren un armazón constructivo que los mantenga siempre en la posición adecuada. Concebir este armazón es la segunda misión del arquitecto." Adolf Loos: El principio del revestimiento, p. 151

${ }^{8}$ Le Corbusier: Le Corbusier et son atelier rue de Sèvre 35: oeuvre complète 1952-1957, pp. 132-133
} 


\section{Suspender las presencias contingentes}

Como señala Josep Quetglas en su texto La línea vertical, Le Corbusier define la casa en la introducción a la segunda edición de Vers une architecture como un bastión fuera del alcance de las embestidas de la naturaleza que le es hostil, que nos acosa:

"Una casa que sea ese límite humano, que nos rodee, que nos separe del fenómeno natural antagonista, que nos dé nuestro medio humano, a nosotros, los hombres9." Le Corbusier

Es en ese mismo sentido que la modernidad trató de suspender el tiempo, ineludible manifestación natural, en sus proyectos. Le Corbusier da cuenta de ello en su texto L'espace indecible, publicado en abril de 1946 y en el que se plantea el ejercicio de describir cuál será la forma más elevada de apropiación y gestión del espacio por parte de la arquitectura:

"No es un efecto del tema elegido, sino una victoria de la proporción en todas las cosas, tanto en los aspectos físicos de la obra como en la eficiencia de las intenciones, reguladas o no, aprehendidas o inaprensibles y, no obstante, existentes y deudoras de la intuición, milagro catalizador de saberes adquiridos, asimilados aunque tal vez olvidados. Pues en una obra concluida con éxito hay masas intencionales ocultas, un verdadero mundo que revela su significado a quien tiene derecho, es decir, a quien lo merece.

Se abre entonces una profundidad sin límites que borra los muros, expulsa las presencias contingentes y realiza el milagro del espacio inefable. ${ }^{10}$ " Le Corbusier

No queda duda al respecto de cuál debe ser el papel de las incertidumbres en la arquitectura: las presencias contingentes serán expulsadas en la búsqueda del éxito pleno de la obra arquitectónica.

La vida del habitante nómada al que Le Corbusier hace depositario de sus tapices está altamente expuesta a la contingencia, a la sucesión de eventos que escapan de su control a priori y que pueden hacer movedizo el espacio que habita. ¿Cómo obviar la presencia de ese tiempo incierto en la casa del habitante nómada, que se ve obligado a construir un nuevo hogar cada vez que su circunstancia le apremia a moverse?

El tapiz se convierte en el dispositivo capaz de permitir que el espacio permanezca inmutable pese a las embestidas de la incertidumbre. El tapiz construye un espacio confortable, equipado. Un lugar que resuelve incluso las aspiraciones poéticas de sus ocupantes. El tapiz suspende el tiempo.

\section{Procedencia de las imágenes}

1. Mayol, Jaume: Arquitectures teixides. No publicado

2. Mayol, Jaume: Arquitectures teixides. No publicado

\section{Bibliografía/referencias}

Le Corbusier: Le Corbusier \& P. Jeanneret: oeuvre complète 1934-1938 / publiee par Max Bill (12th ed.) Zurich: Editions d'Architecture Artemis, 1995

\footnotetext{
${ }^{9}$ Le Corbusier, Vers une architecture. p. XXI

${ }^{10}$ Le Corbusier, El espacio inefable
} 
Le Corbusier: Le Corbusier et son atelier rue de Sèvre 35: oeuvre complète 1952-1957 / publiee par W. Boesiger (9th ed.) Zurich: Editions d'Architecture Artemis, 1995

Le Corbusier: Le Corbusier: les dernières oeuvres [1965-1969] publiee par W. Boesiger (5th ed.). Zurich: Editions d'Architecture Artemis, 1995

Le Corbusier: Vers une architecture. Présentation de Jean-Louis Cohen. París: Flammarion, 2005

Le Corbusier: "El espacio inefable" (Pérez Colina, Marisa trad.). En Minerva. "Dossier Le Corbusier". Marzo 2006, No 2. Madrid: Círculo de Bellas Artes, 2006

Golan, Romy: Muralnomad. The paradox of wall painting, Europe 1927-1957. New Haven, USA: Yale University Press, 2009

Loos, Adolf. "El principio del revestimiento". En Loos, Adolf: Escritos I, 1897-1909. Madrid: Corquis, 1993

Oddo, Maurizio: Le Corbusier: dalla pittura al muralnomad. Palermo: Medina, 1997

Semper, Gottfried: The four elements of architecture and other writings. Cambridge: Cambridge University Press, 1989 